\title{
Abordagem dos Problemas Éticos em Pediatria: Sugestões Advindas da Prática
}

\author{
Approaches to Ethical Problems in Pediatrics: \\ Suggestions Based on Practice
}

Jucélia Maria Guedert ${ }^{I}$ Suely Grosseman

\section{PALAVRAS-CHAVE \\ - Ética \\ - Estratégias \\ - Pediatria \\ - Educação médica.}

- Ethics

- Strategies

- Pediatrics

- Education, Medical.

Recebido em: 19/11/2010

Reencaminhado em: 16/02/2011

Aprovado em: 18/02/2011

REVISTA BRASILEIRA DE EDUCAÇÃO MÉDICA

\section{RESUMO}

No atendimento à criança, os profissionais da saúde lidam com situações geradoras de problemas éticos, que requerem competência para a tomada de decisões. Visando fornecer subsídios ao desenvolvimento dessa competência na graduação em Medicina, o objetivo deste estudo foi analisar estratégias sugeridas por médicos que atuam em ensino e assistência pediátrica para melhor abordagem dos problemas éticos vivenciados no cotidiano profissional. Trata-se de uma pesquisa quali-quantitativa, descritiva, aprovada no CEP-HIJG, com 72 médicos de dois hospitais e 16 da atenção primária, que responderam a um questionário semiestruturado. Realizou-se análise de conteúdo e descritiva com medidas de tendência central. Foram sugeridas como estratégias: abordagem sistemática e reflexão sobre ética e bioética, baseada em problemas cotidianos, na graduação, residência e atuação profissional; maior abordagem do tema em eventos médicos; elaboração de normas e orientações claras sobre problemas éticos; reflexão sobre o tema durante o ensino-aprendizagem e nas relações profissionais; $e$ constituição de grupos especializados para ajudar na tomada de decisões. As estratégias são viáveis e deveriam ser consideradas no planejamento de ações institucionais e educacionais em Pediatria.

In pediatric care, health professionals frequently deal with situations involving ethical problems, which in turn require decision-making skills. In order to support the development of such skills during undergraduate medical training, the aim of this study was to analyze strategies suggested by physicians working in teaching and pediatric care to improve the approach to ethical problems arising in daily practice. This was a descriptive qualitative and quantitative study, approved by the Institutional Review Board of the Joana de Gusmão Pediatric Hospital (HIJG) in Florianópolis, Santa Catarina, Brazil, with 72 physicians from two hospitals and 16 from primary care, who answered a semi-structured interview. Content and descriptive analysis was performed with measures of central tendency. The following strategies were selected: systematic approach and reflection on ethics and bioethics, based on daily problems in undergraduate training, residency, and professional practice; a more extensive approach to the theme in medical events; elaboration of clear standards and guidelines on ethical problems; reflection on the theme during teaching-learning and in professional relations; and the establishment of specialized groups to assist in decision-making. The strategies are feasible and should be considered in planning institutional and educational activities in Pediatrics. 


\section{INTRODUÇÃO}

A ética pode ser definida como a ciência que estuda a conduta e o comportamento humanos, e a ética médica como o estudo crítico dos problemas morais oriundos da prática médica no âmbito da ciência moderna ${ }^{1}$.

A vinculação do ensino à prática assistencial oferece ao aluno a possibilidade de descobrir o universo profissional real, permeado por questões que exigem posicionamento não apenas técnico, mas também ético.

Partindo dos pressupostos de que valores morais podem ser ensinados durante o processo de socialização secundária²; de que, cada vez, mais se reconhece que o ensino da ética deve ser personalizado conforme a disciplina e o nível de aprendizado do aluno; e de que a forma mais eficaz de aprendizagem em ética está diretamente relacionada à assistência, Singer e colaboradores $^{3}$ relacionaram cinco desafios para o ensino da ética nesta década: desenvolvimento de módulos de instrução a serem disponibilizados via internet para divulgação, reprodução e educação à distância; incorporação crescente de conhecimentos à área por meio da educação continuada dos atores envolvidos no cuidado em saúde; desenvolvimento, nos meios acadêmicos, de "uma cultura" sensível às preocupações éticas; entendimento, por educadores médicos, da importância da formação do caráter como elemento central para a vida moral; e incorporação da avaliação de desempenho em ética clínica como parte da avaliação para médicos em todos os níveis.

Esses autores ressaltam ainda a necessidade de capacitar professores, pois, se a ética clínica é mais bem aprendida "à beira do leito" e no cuidado individualizado de pacientes e suas famílias, os professores de clínica precisam ter habilidades para reconhecer e explorar os momentos de atendimento e conduzir eles mesmos o ensino da ética ${ }^{3}$.

Sabe-se que estudantes e médicos mais jovens procuram identificar em seus professores e orientadores as qualidades que gostariam de ter, e esta tem se mostrado uma forma importante de inculcar valores profissionais, atitudes e comportamentos ${ }^{4}$. Estas habilidades são apreendidas principalmente por meio do chamado currículo oculto, e, portanto, a reflexão ética deve estar presente em todo ambiente onde se desenvolve o ensino.

Para Schraiber ${ }^{5}$ a atividade médica contemporânea é criticada pela falta de compromisso profissional, relacionada tanto ao uso incorreto das tecnologias, ao desperdício financeiro e excesso de gastos, como à despersonalização dos cuidados e desumanização da assistência, com inadequada relação médico-paciente e formação insuficiente de vínculos.

Nesse sentido, capacitar estudantes e residentes para torná-los aptos a lidar adequadamente não só com os desafios técnicos, mas também com os inúmeros aspectos éticos que acompanham a profissão tem se mostrado uma preocupação crescente dos envolvidos com a educação médica ${ }^{3,5-9}$.

$\mathrm{O}$ atendimento às crianças e adolescentes envolve interações multidimensionais complexas entre médico, equipe de saúde, pacientes, pais e/ou responsáveis, comunidade e sistema de saúde, que são inseparáveis no momento da tomada de decisão e manejo terapêutico. E este atendimento é fortemente afetado por desigualdades sociais, avanços tecnológicos da área da saúde e questões morais da sociedade, resultando em vivências que, muitas vezes, são geradoras de dilemas éticos ${ }^{1}$.

Os avanços tecnológicos e sociais atuais acarretam a demanda de profissionais capacitados para tomar decisões prudentes frente aos dilemas morais da saúde humana ${ }^{10}$. Problemas desse âmbito, testemunhados por estudantes ${ }^{7,11}$, docentes ${ }^{12}$, profissionais da atenção básica ${ }^{13}$ e de outros contextos ${ }^{14}$, têm sido abordados por pesquisadores.

Especificamente no atendimento à criança no Brasil, existe pouco conhecimento sobre o tema e as ações que podem ser desenvolvidas em nível acadêmico e institucional para ajudar os profissionais a adotar a melhor conduta frente aos questionamentos éticos que emergem do dia a dia da prática médica dedicada a essa faixa etária.

Visando fornecer subsídios à educação médica, o objetivo deste estudo foi analisar estratégias sugeridas por médicos atuantes em ensino e assistência às crianças e adolescentes, para melhor abordagem dos problemas éticos vivenciados no cotidiano.

\section{MÉTODO}

Trata-se de um estudo transversal, descritivo, que utilizou metodologia qualitativa exploratória e quantitativa. A abordagem qualitativa foi escolhida por permitir ao pesquisador compreender melhor os significados dos sujeitos da investigação a partir da perspectiva destes ${ }^{15}$.

A população de estudo foi composta por médicos que exerciam atividades de assistência às crianças e adolescentes e de educação médica (graduação e/ou residência) em hospitais de ensino e Unidades Básicas de Saúde (UBS). O universo de 173 médicos foi identificado a partir da lista fornecida pelos setores gerenciais, sendo 136 das unidades hospitalares e 37 de UBS integrantes da rede docente-assistencial.

$\mathrm{O}$ critério de inclusão adotado foi exercer concomitantemente atividades de atendimento pediátrico e de ensino médico. Os critérios de exclusão foram: ser residente, estar aposentado ou licenciado, não ter contato direto com formação em Pediatria e não atender crianças.

Após aprovação pelo Comitê de Ética em Pesquisa do Hospital Infantil Joana de Gusmão (Parecer 032/2008), foi realizado estudo piloto com 15 médicos elegíveis. 
O instrumento de coleta de dados foi um questionário semiestruturado, autoaplicado e dividido em três partes: a primeira, com dados sociodemográficos, de formação e atuação profissional; a segunda, com roteiro baseado em Taquette et al. ${ }^{11} \mathrm{e}$ adaptado para a população de estudo, solicitava relatos de até três situações vivenciadas no atendimento à criança que tenham representado dilemas éticos, sentimentos em relação a elas, quem ou o que poderia ajudar, subsídios utilizados na tomada de decisão e encaminhamento dado; a terceira parte solicitava aos participantes a indicação de estratégias que poderiam ser desenvolvidas para melhor abordagem dessas situações. Este estudo se detém com maior ênfase na última parte desse questionário.

Inicialmente, 110 médicos foram convidados a participar do estudo. Dois recusaram o convite e 20 (18,5\%) dos que receberam o questionário não o responderam: 16 dos 88 participantes dos hospitais (18,2\%) e 4 dos 20 participantes das UBS (20\%). Dessa forma, participaram efetivamente da pesquisa 72 médicos de dois hospitais de ensino e 16 médicos de 12 UBS da rede docente-assistencial local.

A intenção inicial era ampliar o convite para o universo de estudo. Mas, a partir do sexagésimo questionário recebido, observou-se a escassez de novas categorias, caracterizando a saturação dos dados ${ }^{15,16}$. Ainda assim, mais 28 questionários foram aplicados, para garantia da saturação.

Optou-se por usar a expressão "dilema ético" no instrumento de pesquisa por ser a mais utilizada, na área médica, para as situações que as autoras pretendiam estudar ${ }^{17}$. Entretanto, o entendimento do que seriam situações eticamente dilemáticas ficou a critério dos entrevistados. Dessa forma, foram relatados, do ponto de vista conceitual, dilemas - situação que aponta duas possibilidades, e só uma delas pode ser correta $^{17}$ - ou simplesmente problemas éticos - conceito mais abrangente, que envolve questões abertas para as quais nem sempre somos capazes de apontar soluções ${ }^{17}$. Esta expressão foi escolhida para a redação do presente artigo, para englobar todas as situações relatadas.

Os dados quantitativos foram introduzidos em banco de dados e analisados descritivamente (porcentagem, média aritmética, intervalo de confiança e desvio-padrão), utilizando-se o programa EpiData Analysis. Os dados qualitativos foram analisados por análise temática de conteúdo ${ }^{16}$. As grandes categorias emergentes, suas subcategorias e as "sub-subcategorias" estão descritas nos resultados, respectivamente, em negrito, negrito-itálico e itálico.

\section{RESULTADOS}

A idade média dos participantes foi 44,1 anos $(\mathrm{DP}= \pm 9,2)$. O tempo médio de atuação como médico foi 19,6 anos (DP
$= \pm 9,1)$. O tempo médio diário ocupado com assistência aos pacientes foi 6,8 horas ( $\mathrm{DP}= \pm 2,7$ ), e com o ensino médico 2,3 $(\mathrm{DP}= \pm 2,3)$. As demais características do perfil dos entrevistados estão dispostas na Tabela 1.

TABELA 1

Perfil dos médicos entrevistados (Florianópolis, Santa Catarina - Brasil)

\begin{tabular}{lcrc}
\hline \multicolumn{1}{c}{ Variável } & n & $\%$ & IC 95\% \\
\hline Sexo $(\mathrm{n}=88)$ & & & \\
$\quad$ Masculino & 38 & 43,2 & $33,3-53,6$ \\
$\quad$ Feminino & 50 & 56,8 & $46,4-66,7$ \\
Estado civil $(\mathrm{n}=88)$ & & & \\
$\quad$ Solteiro & 18 & 20,4 & $13,3-30,0$ \\
$\quad$ Casado & 60 & 68,2 & $57,7-77,0$ \\
$\quad$ Divorciado & 8 & 9,1 & $4,7-16,9$ \\
$\quad$ Outro & 2 & 2,3 & $0,6-7,9$ \\
Crença religiosa (n = 88) & & & \\
$\quad$ Sim & 72 & 81,8 & $72,5-88,5$ \\
$\quad$ Não & 16 & 18,2 & $11,5-27,5$ \\
Residência médica (n=88) & & & \\
$\quad$ Sim & 85 & 96,6 & $90,5-98,8$ \\
$\quad$ Não & 3 & 3,4 & $1,2-9,5$ \\
Especialidade médica (n = 88) & & & \\
$\quad$ Pediatria e suas áreas de atuação* & 74 & 84,1 & $75,0-90,3$ \\
$\quad$ Medicina de Família e Comunidade & 14 & 15,9 & $9,7-21,0$ \\
Como atua em Pediatria (n = 74) & & & \\
$\quad \begin{array}{l}\text { Pediatria Geral } \\
\quad \text { Pediatria e suas áreas de atuação* }\end{array}$ & 16 & 21,6 & $13,8-32,3$ \\
$\quad$ Só em áreas de atuação pediátricas* & 31 & 41,9 & $31,3-53,3$ \\
\hline
\end{tabular}

Nota: * Cinquenta e oito participantes, assim distribuídos: Neonatologia (11); Terapia Intensiva (6); Onco-hematologia (5); Endocrinologia, Cardiologia e Neurologia (4); Infectologia, Dermatologia, Medicina do Adolescente e Nutrologia (3); Reumatologia, Gastroenterologia e Cirurgia Pediátrica (2); Pneumologia, Alergia e Imunologia, Genética Clínica, Nefrologia, Psiquiatria e Ortopedia (1).

Quanto à formação/informação em ética e bioética, 37 entrevistados (43,0\%) referiram ter, pelo menos, alguma delas.

Foram relatados 210 problemas éticos. Estes abrangeram os âmbitos: pessoal da relação médico-paciente (principalmente confidencialidade, relações pessoais difíceis e revelações diagnósticas); das condutas de profissionais de saúde e áreas afins (por discordância de indicações terapêuticas ou atitudes de médicos do mesmo serviço ou não, e abrangendo atitudes de outros profissionais); das situações limítrofes (envolvendo tomada de decisões em situações terminais, acatar decisões da equipe e de pacientes e lidar emocionalmente com as situações); socioeconômico e das políticas públicas de saúde (relacionadas principalmente a condições socioeconô- 
micas desfavoráveis, inadequação da rede de atenção à saúde e do ambiente de trabalho, e violência contra a criança) e do ensino em Pediatria (nas relações interpessoais que incluem relação aluno-professor/supervisor, professor-supervisor/paciente, entre professor-supervisor, entre aluno/paciente, entre médicos das Unidades Básicas de Saúde/professores, e nas atitudes pessoais de alunos da graduação e residentes).

O enfrentamento das situações problemáticas fez aflorar nos médicos sentimentos, em sua maioria, causadores de sofrimento, como angústia, desapontamento, impotência, raiva e tristeza, mas também os de solidariedade, compaixão e necessidade de proteger a criança.

Para a tomada de decisão, foram considerados os valores próprios, o Código de Ética Médica, as leis de proteção à criança, a avaliação clínica do paciente e discussões com colegas.

Oitenta e sete entrevistados indicaram estratégias e sugestões para desenvolver habilidades e competências na abordagem dos problemas éticos (Tabela 2).

\section{TABELA 2}

Estratégias sugeridas para o desenvolvimento de habilidades para abordagem de problemas éticos em Pediatria

(Florianópolis, Santa Catarina - Brasil)

\begin{tabular}{lr}
\hline \multicolumn{1}{c}{ Estratégias } & \multicolumn{1}{c}{$\mathbf{n}(\mathbf{\%})^{*}$} \\
\hline Ensino da ética e da bioética & $79^{+}(52,7)$ \\
Apoio & $42(28)$ \\
Atenção aos valores humanísticos & $18(12)$ \\
Diálogo entre os envolvidos & $11(7,3)$ \\
Total & $150(100)$ \\
\hline
\end{tabular}

Nota: * Sugestões de 87 participantes, pois um participante disse não saber.

† Durante a atuação profissional: 48; no ensino formal: 31 .

O ensino da ética e da bioética foi a estratégia mais citada, abrangendo ações a serem desenvolvidas no ensino formal, sendo enfatizada a necessidade do investimento da educação médica em ética e bioética durante todo o transcorrer da formação universitária e residência. Quanto à forma como este deve ocorrer, houve menção à inclusão do tema no currículo médico e nos programas de residência, de ter a ética e bioética como eixo transdisciplinar, e da sua vinculação com as situações concretas vivenciadas pelo estudante. Para possibilitar este ensino, foi mencionada a importância da capacitação dos professores. A narrativa de um dos entrevistados ilustra esta categoria:

"Durante a graduação a minha formação nessa área não foi boa: as aulas absolutamente desinteressantes, professores com grande viés religioso... Durante as residências e na vida, aprendemos a lidar com estas situações praticamente sozinhos, observando os outros, inclusive os que não atuam eticamente. Estas questões tendem a ser encaradas de forma "sentimentaloide" e muitas vezes hipócrita [...]"

Foi citada ainda a necessidade de disciplinas como filosofia e psicologia, além da criação de espaços de discussão do tema nas disciplinas tradicionais da educação médica:

"Ser mais bem estudada a disciplina de ética durante o curso de Medicina, não somente no início, mas também no transcorrer e término do curso. Promover análise de situações clínicas e discussões. É fundamental que na grade curricular de Medicina haja a disciplina de psicologia, principalmente nas últimas fases, promovendo debates frente às situações e seus enfrentamentos."

Foram consideradas estratégias envolvendo ações educativas em ética e bioética no âmbito da atuação profissional. Como possibilidades pontuais foram elencadas a organização de eventos (congressos, seminários, cursos) especificamente sobre ética e bioética, e a abordagem desses temas em eventos médicos gerais ou de especialidades.

As estratégias mais abordadas envolveram um continuum educacional inserido nas atividades habituais médicas, como enfocar aspectos bioéticos nas discussões e visitas clínicas, e formar espaços, nas instituições de saúde, para discussão e reflexão permanente sobre bioética, ressaltando a necessidade da capacitação para a atuação interdisciplinar. O relato de um dos entrevistados é elucidativo:

"Os dilemas éticos surgem comumente em situações complexas, como violência, doenças crônicas e graves, problemas psicossociais. Deve-se estimular a criação e manutenção de espaços regulares de discussão entre profissionais e entre equipes sobre os "encontros difíceis" ou atendimentos complexos, nos moldes de algumas experiências locais com grupos reflexivos... de profissionais de atenção básica."

Foi referida também a importância de cultuar uma relação interpessoal ética no cotidiano da prática assistencial e do ensino:

"A ética deve ser ensinada durante toda a formação do médico e sua especialização, de forma atual e através da vivência no dia a dia. Envolve não só a relação médico-paciente-família, mas a relação médico-médico e outros profissionais da saúde."

Outra estratégia sugerida foi a implementação de apoio institucional com a criação de grupo especializado em étical 
bioética, assessoria jurídica e de órgãos de classe, relacionada à existência de equipes de especialistas em ética e bioética nas instituições de saúde. Neste sentido, foi mencionada a criação de instâncias institucionais permanentes, como comitês, conselhos deliberativos, comissões hospitalares de ética, grupos de discussão envolvendo equipe multidisciplinar, a fim de aprofundar a discussão e auxiliar o médico e sua equipe na tomada de decisão em casos que envolvam problemas éticos. Foi aventada ainda a possibilidade de haver, nos hospitais, uma equipe (plantão, sobreaviso ou grupo de apoio) para esclarecimento de dúvidas e orientações durante ou após o atendimento a situações eticamente difíceis, sobre a tomada de uma atitude e suas implicações, como destacado por um dos entrevistados:

\footnotetext{
"Comunicação entre as equipes de diversos serviços e com os pais. Reuniões para discussão interdisciplinar de casos clinicos difíceis. Estímulo à formação de equipe de bioética para definição destes casos complicados."
}

No ambiente da pesquisa, emerge a necessidade de $\mathbf{a m}$ paro legal em situações conflituosas, com possibilidade de assessoria jurídica, participação mais efetiva dos conselhos de medicina nas instituições de saúde, maior atenção dos gestores de políticas públicas para as necessidades dos pacientes, possibilidade de um profissional e site na internet para esclarecimento rápido de dúvidas sobre o tema. Foi ressaltado ainda que o médico envolvido nessas situações precisa ter orientações claras de como agir, fornecidas por seus órgãos de classe, e uma padronização de condutas, avalizada pela instituição:

\begin{abstract}
"Acho sempre que devemos nos guiar pelos conceitos éticos que conhecemos e, quando houver dúvidas profissionais, (ter) advogados ou CRM para nos auxiliar, porém sempre com cautela, tentando não piorar ainda mais o andamento. Acho que poderíamos ter um site na internet para podermos tirar dúvidas específicas, já que hoje temos acesso mais fácil."
\end{abstract}

Em casos que envolvam óbitos, foi sugerida a criação de grupo de apoio aos pais.

Na atenção primária, foi sugerida a incorporação da bioética no apoio matricial da Estratégia de Saúde da Família e a necessidade de recursos para enfrentamento das situações de violência, como relatado por um médico de Unidade Básica de Saúde:

"Incorporação desta temática às estratégias de apoio matricial ou Pediatria, com suporte institucional... Identificação e ativação de rede de equipamentos públicos e recursos comunitários para lidar com situações como violência. Supervisão institucional das equipes de saúde da família para lidar com atendimentos difíceis e casos complexos que gerem dilemas."

Atenção aos valores humanísticos foi uma estratégia apontada, abrangendo humanização, valores morais próprios e melhora na relação médico-paciente. Aqui surge a necessidade de serem trabalhados, na prática diária, e no ensino formal, os temas: respeito ao paciente, diálogo franco com as famílias, aumento da tolerância, flexibilidade, generosidade, bom senso, sensibilidade, humildade e a boa relação não só médico-paciente-família, mas também com outros profissionais da saúde. A citação a seguir traduz e justifica a escolha do termo "valores humanísticos" para esta categoria:

"A compreensão da realidade social, econômica, educacional, cultural dos pacientes, e o respeito a isso. A responsabilidade dos profissionais de saúde pelos pacientes. A individualização das consultas. Não esquecer que somos cuidadores e, por isso, responsáveis pelos pacientes. Falta muita compaixão, responsabilidade e amor pela vida humana. Pode-se não saber toda a técnica, mas, se erramos na responsabilidade, no amor, nunca acertaremos em nada."

O diálogo entre os profissionais envolvidos foi apontado e inclui a necessidade de manter a boa comunicação com colegas de trabalho e com outros serviços de saúde, reuniões freqüentes e discussão dos casos com a equipe envolvida no atendimento à criança.

\section{DISCUSSÃO}

Os problemas éticos que emergiram no contexto deste estudo mostram que nesta área ocorre a conjunção de dilemas e conflitos que vão além dos descritos no atendimento à saúde em geral e daqueles que já se tornaram "os clássicos da bioética", como os que envolvem a não introdução e retirada de suporte avançado de vida e os relacionados a transfusões de sangue em testemunhas de Jeová.

Muitos problemas éticos que ocorrem no atendimento à saúde de crianças e adolescentes são específicos desta população e por isso requerem especial atenção dos educadores em Pediatria, uma vez que os profissionais precisam estar preparados para lidar adequadamente com eles. Ressalta-se a questão da autonomia desses pacientes, o limite de viabilidade de prematuros, as ordens de não reanimar bebês nascidos com deformidades incompatíveis com a vida, as doenças genéticas, a emergência de terapias de altíssimo custo e os dilemas oriundos da assistência às crianças com quadros neurológicos progressivos ou severos com grande comprometimento de sua qualidade de vida. 
A importância do ensino formal da ética e da bioética é inquestionável. Merece destaque que menos da metade dos participantes referiu ter formação/informação nessas áreas.

Sabemos que a incorporação da bioética como disciplina acadêmica é recente, e nossos entrevistados tinham, em média, quase vinte anos de formados. De qualquer forma, temos que admitir uma grande lacuna de conhecimento. Talvez por isso, a menção da necessidade de conhecimentos sobre o tema tenha sido tão valorizada como estratégia para melhor abordagem dos problemas elencados.

A educação em ética tornou-se requisito básico de qualquer programa de formação para profissionais de saúde e deve envolver graduação, pós-graduação e educação continuada. Tanto seus fundamentos teóricos como as habilidades práticas são necessários para raciocínio, postura ética e tomada de decisão adequada ${ }^{18}$.

Em revisão realizada, Miles et al. ${ }^{19}$ identificaram cinco principais objetivos do ensino da ética aos médicos:

Ensinar a conhecerem aspectos éticos e humanísticos de sua carreira; permitir examinar e afirmar seus compromissos morais pessoais e profissionais; dotá-los de uma base filosófica, social e de conhecimentos jurídicos; permitir que usem esse conhecimento no raciocínio clínico e fornecer habilidades necessárias para aplicar essa percepção, conhecimento e raciocínio no cuidado de seres humanos. (p.706)

Concordamos com Rego ${ }^{20}$ quando afirma que a formação do médico deve ir além da mera transmissão de conhecimentos e avançar com a "transmissão de valores e normas como parte da socialização do futuro médico" (p. 197). Ainda para esse autor, duas questões são estratégicas na formação de profissionais de saúde: "desenvolver a sua capacidade de realizar julgamentos morais de forma autônoma e aprofundar sua capacidade de análise ética com os recursos que a filosofia oferece" $^{\prime 20}$ (p. 196).

Para o ensino adequado dessas competências, não é possível ministrar aulas em que o aluno recebe passivamente as informações e não é estimulado a refletir sobre os diferentes valores morais em jogo. O que se preconiza é que a discussão bioética permeie todos os momentos possíveis da formação ${ }^{10}$, inserida transversalmente em todas as disciplinas ${ }^{7}$.

Cabe destacar o papel desempenhado pelo chamado "currículo oculto" na formação moral do estudante de Medicina. Como ele se caracteriza pelo amplo conjunto de experiências formativas que ocorrem involuntariamente e que interferem principalmente no desenvolvimento de valores e atitudes ${ }^{21}$, é onde podemos perceber a importância da competência moral dos professores e supervisores, como são nossos entrevistados.

Tendo como pano de fundo a exuberante velocidade com que ocorrem as transformações sociais atuais, a formação profissional não pode mais estar limitada ao ensino formal. Ela deve se estender, conforme Ribeiro"22 "ao longo de todas as trajetórias pessoais, sociais e profissionais, ultrapassando as tradicionais fronteiras espaço-temporais delimitadas institucionalmente pelos sistemas de educação/formação" (p. 51).

Partindo desse pressuposto, percebemos a importância da educação permanente do ponto de vista não só técnico, hoje predominante ${ }^{23,24}$, como também das habilidades de comunicação e desenvolvimento ético.

Para Ceccim e Feuerwerker ${ }^{25}$,

o trabalho em saúde é um trabalho de escuta, em que a interação entre o profissional de saúde e o usuário é determinante na qualidade da resposta assistencial, A incorporação de novidade tecnológica é constante e novos processos decisórios repercutem na concretização da responsabilidade tecnocientífica, social e ética do cuidado, do tratamento ou do acompanhamento em saúde. A área da saúde requer educação permanente. (p. 49)

A utilização do termo "educação permanente" é o adotado pelo governo brasileiro em sua Política Nacional de Educação Permanente em Saúde. Ela se caracteriza como um processo de aprendizagem-trabalho, que ocorre no cotidiano das pessoas e das organizações a partir dos problemas enfrentados e considerando conhecimentos e experiências adquiridos. Propõe que as ações educativas se façam a partir da problematização do processo de trabalho e considera que as necessidades de formação e desenvolvimento dos trabalhadores sejam pautadas pelas necessidades de saúde das pessoas e populações ${ }^{26}$.

Essa proposta educativa está em consonância com a estratégia de formação proposta pelos entrevistados. Considerando que esta pesquisa foi realizada em diferentes ambientes do Sistema Único de Saúde, na atenção hospitalar ficou evidente a necessidade de ações educativas que envolvam os problemas éticos das relações interpessoais, da relação médico-paciente e dos cuidados de pacientes gravemente enfermos. Na atenção primária, foram sugeridas ações que abrangem a questão da violência, o uso de drogas, as políticas públicas e o acesso aos serviços de saúde.

Entendemos que as atividades educativas em bioética realizadas na formação acadêmica e na educação permanente exigem também a capacitação de professores e supervisores. Para 
isto, é necessário também estender o processo ao desenvolvimento docente, uma vez que a integração da formação ética na universidade requer mudanças culturais, e sua necessidade ainda não é sentida e compartilhada por toda a comunidade universitária ${ }^{27}$.

Assim como médicos e profissionais de saúde estão sendo cada vez mais desafiados sobre a base de evidências para decisões clínicas, também há crescente atenção sobre a dimensão ética do cuidado. Sabidamente, em muitas situações, a simples aplicação dos tradicionais princípios de Beauchamp e Childress - respeito à autonomia, beneficência, não maleficência e justiça - não é suficiente para a análise da dimensão ética desses problemas. Tradicionalmente, os médicos têm solicitado apoio de colegas mais experientes, mas progressivamente, pela ampliação da prática multidisciplinar, outros profissionais estão sendo incluídos nas discussões e decisões ${ }^{28}$. Isto ficou evidenciado na sugestão de estratégia que envolva a criação de grupos especializados em ética/bioética.

Estes grupos podem ser traduzidos pelos comitês institucionais de bioética ( $\mathrm{CHB})$, que correspondem a um grupo interdisciplinar composto por profissionais de saúde e de outros campos do conhecimento e membros da comunidade, com a função de aconselhar, consultar, discutir ou estar, de algum modo, envolvido nas decisões e políticas relacionadas com temas éticos que surgem na atenção à saúde ${ }^{29}$.

Dentre as possíveis funções do CHB, destacam-se a educativa, a formuladora de políticas e a consultiva ${ }^{30}$. A educativa abrangeria os âmbitos do próprio comitê, o grupo de trabalhadores da instituição e a população em geral, e nessa função podem ser propostas ações que contemplem a educação permanente; a normativa diz respeito à possibilidade de intervir em regulamentações da instituição; e na atividade consultiva o CHB entraria como apoiador do profissional ou da equipe de cuidado.

O apoio matricial em saúde objetiva assegurar retaguarda especializada às equipes e profissionais encarregados da atenção a problemas de saúde ${ }^{31}$. O apoiador matricial é um especialista que tem um núcleo de conhecimento e um perfil distinto daquele dos profissionais de referência e pode agregar recursos de saber e contribuir com intervenções que aumentem a capacidade resolutiva da equipe primariamente responsável pelo caso ${ }^{31}$. Ele poderia ser um profissional com conhecimentos em bioética.

O recurso judicial para resolução de conflitos éticos deve ser excepcional e reservado às situações em que as discordâncias entre os envolvidos sejam insolúveis e possam ter importantes consequências práticas ${ }^{14}$. Em ocasiões que envolvam questões legais - como nas ações de responsabilização, no en- frentamento de casos de violência e, no caso de atendimento às crianças, em situações em que se estabelece um conflito entre a equipe profissional e os pais -, há necessidade de apoio de uma assessoria jurídica. Convém ressaltar que nos locais onde a pesquisa foi realizada os profissionais não podiam contar diretamente com esse apoio.

A prática médica do final do século XIX e início do século XX associava as condutas clínicas às morais. A relação médico-paciente era individualizada, o paciente era percebido como um todo indivisível, e habilidade e sensibilidade eram os principais atributos para o exercício da medicina. O desenvolvimento científico e tecnológico ocorrido no século passado influenciou significativamente a atividade médica: a tecnologia e a racionalização do trabalho começaram a concorrer com a subjetividade, a intuição, a individualização e a sensibilidade na relação médico-paciente ${ }^{32}$. Assim, a medicina foi deixando de lado a escuta dos problemas, o humanismo e a unicidade humana, acarretando profundas mudanças também no ensino médico ${ }^{33}$.

Buscando alternativas para resgatar valores morais importantes para a atividade do cuidado à saúde, vários movimentos surgiram, como o da reforma sanitária, o estabelecimento do SUS, o nascimento da bioética e dos direitos humanos, e várias iniciativas com o nome de humanização ${ }^{33,34}$. Para $\operatorname{Rios}^{34}$,

a humanização se fundamenta no respeito e valorização da pessoa humana, e constitui um processo que visa à transformação da cultura institucional por meio da construção coletiva de compromissos éticos e de métodos para as ações de atenção à saúde e de gestão de serviços [...] Participação, autonomia, responsabilidade e atitude solidária são valores que caracterizam esse modo de fazer saúde que resulta, ao final, em mais qualidade na atenção e melhores condições de trabalho. Sua essência é a aliança da competência técnica e tecnológica com a competência ética e relacional. (p. 255)

O pediatra não ficou imune às dificuldades vividas na prestação de cuidados de saúde na sociedade contemporânea. A ele cabe cuidar de cada vez mais pacientes, com mais complicadas histórias médicas e sociais, usando mais tecnologia e menos tempo para o atendimento, aumentando o risco de perder de vista o que o motivou para a profissão: o desejo de cuidar de crianças e de suas famílias ${ }^{35}$.

Nesse sentido, os participantes citaram a atenção aos valores humanísticos como estratégia de enfrentamento de muitos dos problemas éticos vivenciados. Tais valores abrangem tanto "valores e princípios morais próprios", adquiridos nos processos de socialização primária e secundária ${ }^{2}$ e influencia- 
dos pela cultura, como os da política de humanização - autonomia, justiça, corresponsabilidade entre os sujeitos, estabelecimento de vínculos solidários e participação coletiva no processo de gestão ${ }^{36}$ - e também os envolvidos nas adequadas formas de estabelecimento e manutenção da relação médico-criança-família.

Sobre esse tema, recentemente a Academia Americana de Pediatria ${ }^{35,37}$ apresentou o que seriam padrões ideais de comportamento e de prática profissional para o pediatra, que deveriam ser utilizados no ensino e serviriam de base para avaliar estudantes e residentes. $\mathrm{O}$ documento delineia os principais valores morais norteadores do cuidado às crianças e suas famílias, definidos como profissionalismo em Pediatria. Aquela instituição definiu um conjunto de oito princípios que comporiam um núcleo para ensino e avaliação de residentes: honestidade e integridade; confiabilidade e responsabilidade; respeito pelos outros; compaixão/empatia; autoaperfeiçoamento (preocupação com educação permanente); consciência/conhecimento dos próprios limites; comunicação e colaboração; altruísmo e apoio ao outro ${ }^{35}$.

Em outra publicação, além desses princípios, a Academia Americana de Pediatria enfatiza como valores essenciais à prática médica: responsabilidade com pacientes e famílias, responsabilidade com os outros profissionais da saúde e de serviços de apoio, responsabilidade com a comunidade e também com a própria profissão ${ }^{37}$.

O professor Edgar Morin, em Os sete saberes necessários à educação do futuro, trata das interdependências humanas que se multiplicam, do triunfo da comunicação (pelas redes, fax, telefonia, internet, etc.), e da incompreensão, que parece ser ainda maior ${ }^{38}$.

Com todo o mundo interligado, tudo o que acontece afetará a todos de uma ou outra forma. O mundo precisa de mais compreensão mútua, intercâmbios pacíficos e harmonia. "Trata-se de aprender a viver conjuntamente, desenvolvendo o conhecimento dos outros, de sua história, de suas tradições e de sua espiritualidade" ${ }^{\prime \prime 39}$ (p. 78). Nos espaços de cuidado à saúde interagem profissionais de diferentes áreas de conhecimento, e a educação médica tem sido desafiada no ensino das habilidades para o trabalho interdisciplinar ${ }^{40}$.

Do ponto de vista filosófico, Karl-Otto Appel e Jürgen Habermas, criadores da ética do discurso, estabeleceram que a razão moral é uma razão prática dialógica, uma racionalidade comunicativa, ou seja, é por meio do diálogo estabelecido entre todos os afetados pelas normas, e não individualmente, que devemos concluir que uma norma é uma lei moral ou correta. Assim sendo, saber se comportar moralmente significa dialogar a sério na hora de decidir as normas, considerando que qualquer pessoa afetada por elas é um interlocutor válido e deve ser tratado como tal ${ }^{41}$.

Na atividade médica, a comunicação exige grande capacidade, principalmente nas situações de difíceis tomadas de decisão, quando tanto a técnica e o conhecimento acadêmico, quanto a ética e a sensibilidade individual estão envolvidos. Um estudo sobre a comunicação entre médicos e familiares de crianças em UTI mostrou, dentre outros fatos, a ausência desta e a necessidade de debate e reflexão de cunho interdisciplinar, em nível institucional e acadêmico, sobre a relação médico-paciente e a comunicação frente aos dilemas éticos vivenciados $^{42}$

No âmbito hospitalar e na atenção básica, foram sugeridas estratégias que demonstram a importância das habilidades comunicacionais nesses ambientes, tanto para estabelecer relações interpessoais adequadas, como para resolver conflitos que delas emergem e buscar, de forma compartilhada, a melhor tomada de decisão.

\section{CONSIDERAÇÕES FINAIS}

As estratégias elencadas podem ser desenvolvidas em qualquer cenário - Pediatria, medicina de família, outras áreas dos serviços de saúde, ambiente hospitalar ou ambientes de atenção básica -, reforçando a importância de que a reflexão ética permeie todas as atividades e relações dos atores sociais no ambiente da educação e da prática médica.

A necessidade de apoio em situações difíceis revelou a premência de viabilizar em nível institucional mecanismos de auxílio aos profissionais na tomada de decisões. Valores humanísticos devem perpassar todo o cuidado à saúde. O diálogo é uma importante ferramenta ética na relação médico-paciente e nas relações interpessoais.

Estas estratégias são viáveis e devem ser consideradas pelas instituições de ensino e de atenção à saúde no planejamento das ações, tendo em vista a vivência cotidiana de problemas éticos e a responsabilidade de tomar decisões que beneficiem a integridade profissional e o bem-estar social.

\section{REFERÊNCIAS}

1. Schonhaut B L, Carvajal H C. Dimensões e dilemas de la ética en educación en ciencias de la salud. Rev Chil Pediatr. 2007;78:196-201.

2. Berger PL, Luckmann T. A construção social da realidade. 27aㅡ ed. Petrópolis: Vozes; 2007.

3. Singer PA, Pellegrino ED, Siegler M. Clinical ethics revisited. BMC Medical Ethics [periódico na Internet].2001. [acessoem 26 set. 2010]; 1-8. Disponível em: http:/ /www. biomedcentral.com/content/pdf/1472-6939-2-1.pdf 
4. Paice E, Heard S, Moss F. How important are role models in making good doctors? BMJ 2002;325:707-10.

5. Schraiber LB. No encontro da técnica com a ética: o exercício de julgar e decidir no cotidiano do trabalho em Medicina. Interface Comun Saúde Educ. 1997;1:123-40.

6. Gomes AMA, Moura ERF, Amorim RF. O lugar da ética e bioética nos currículos de formação médica. Rev Bras Educ Med [periódico na Internet].2006 [acesso em 26 set. 2010];30(2):56-65. Disponível em: http://www.scielo.br/ pdf/rbem/v30n2/v30n2a08.pdf

7. Rego S. A formação ética dos médicos: saindo da adolescência com a vida (dos outros) nas mãos. Rio de Janeiro: Fiocruz; 2003.

8. Roberts LW, Warner TD, Hammond KA, Geppert CM, Heinrich T. Becoming a good doctor: perceived need for ethics training focused on practical and professional development topics. Acad Psychiatry. 2005;29(3):301-9.

9. Siqueira JE. Educação médica em bioética. Rev Bras Bioética. 2007;3(3):301-27.

10. Siqueira JE. O ensino da ética no curso de medicina. Mundo Saúde [periódico na Internet]. 2009 [acesso em 15 set. 2010];33(1):8-20. Disponível em: http://www.saocamilo-sp.br/pdf/mundo_saude/66/8a20.pdf

11. Taquette SR, Rego S, Schramm FR, Soares LL, Carvalho SV. Situações eticamente conflituosas vivenciadas por estudantes de medicina. Rev Assoc Med Bras. [periódico na Internet].2005 [acesso em 3 mar. 2008];51(1):23-8. Disponível em: http://www.scielo.br/pdf/ramb/v51n1/a15v51n1. pdf

12. Serodio AMB, Almeida JAM. Situações de conflitos éticos relevantes para a discussão com estudantes de medicina: uma visão docente. Rev Bras Educ Med. [periódico na intenet]. 2009. [acesso em 8 fev. 2010]; 33(1):55-62. Disponível em: http://www.scielo.br/pdf/rbem/v33n1/08.pdf

13. Zoboli ELCP, Fortes PAC. Bioética e atenção básica: um perfil dos problemas éticos vividos por enfermeiros e médicos do Programa Saúde da Família, São Paulo, Brasil. Cad Saúde Pública. [periódico na Internet]. 2004 [acesso em 17 set. 2009];20(6):1690-9.

14. Gonzáles AH, Tezanos MTH, Rastrollo RH, et al. Encuesta de ética en las unidades de cuidados intensivos pediátricos españolas. An Pediatr (Barc). 2006;64:542-9.

15. Bogdan R, Biklen S. Investigação qualitativa em educação: uma introdução à teoria e aos métodos. Porto: Porto Editora; 1999.

16. Minayo MCS. O desafio do conhecimento: pesquisa qualitativa em saúde. $6^{\text {a }}$ ed. São Paulo-Rio de Janeiro: Hucitec-Abrasco; 1999.
17. Gracia D. La deliberación moral: o papel de las metodologías en ética clínica. In: Albarezude JS, López MR, eds. Jornada de debate sobre comités assistenciales de ética. Madri: Asociación de Bioética Fundamental y Clínica; 2000.

18. Hattab AS. Current trends in teaching ethics of healthcare practices. Develop World Bioeth 2004;4(2):160-72.

19. Miles SH, Lane LW, Bickel J, Walker RM, Cassel CK. Medical ethics education: coming of age. Acad Med. 1989;64(12):705-14.

20. Rego S, Costa-Macedo L. Subsídios para a educação moral nos cursos de graduação em saúde. In: Schramm FR, Rego S, Braz M, Palácios M, org. Bioética: riscos e proteção. Rio de Janeiro: UERJ/Fiocruz; 2009:193-210.

21. Tavares CHF, Maia JA, Muniz MCH, Malta MV, Magalhães BRC, Thomaz ACP. O currículo paralelo dos estudantes da terceira série do curso médico da Universidade Federal de Alagoas. Rev Bras Educ Med [periódico na Internet]. 2007 [acesso em 2 set. 2009];31(3):245-53.

22. Ribeiro R. O trabalho como princípio educativo: algumas reflexões. Saúde Soc. 2009;18(Supl.2):48-54.

23. Peduzzi M, Guerra DAD, Braga CP, Lucena FS, Silva JAM. Atividades educativas de trabalhadores na atenção primária: concepções de educação permanente e de educação continuada em saúde presentes no cotidiano de Unidades Básicas de Saúde em São Paulo. Interface Comun Saúde Educ. 2009;13(39):121-34.

24. Tronchin DMR, Mira VL, Peduzzi M, et al. Educação permanente de profissionais de saúde em instituições públicas hospitalares. Rev Esc Enferm USP. 2009;43(Esp 2):1210-5.

25. Ceccim RB, Feuerwerker LCM. O quadrilátero da formação para a área da saúde: ensino, gestão, atenção e controle social. Physis (Rio J.) [periódico na internet].2004 [acesso em 18 ago. 2010];14(1):45-65.

26. Brasil. Ministério da Saúde. Política nacional de educação permanente em saúde. Brasília:MS; 2009. Disponível em: http://bvsms.saude.gov.br/bvs/publicacoes/politica_nacional_educacao_permanente_saude.pdf

27. Martínez MM, Buxarrais MR, Esteban F. La universidad como espacio de aprendizaje ético. Rev Iberoamericana de Educación. 2002;29:17-43.

28. Waterston T, Goldhagen J. Why children's rights are central to international child health. Arch Dis Child. 2007;92:17680.

29. Vidal SM. Los comités hospitalarios de bioética (Introdución a la bioética institucional). In: II Curso de Bioética Clinica y Social - Material obrigatório - Módulo III PEPB — Rev Bioetica. UNESCO:1-39. 
30. Rego S, Palácios M, Siqueira-Batista R. Bioética para profissionais da saúde. Rio de Janeiro: Fiocruz; 2009.

31. Campos GWS, Domitti AC. Apoio matricial e equipe de referência: uma metodologia para gestão do trabalho interdisciplinar em saúde. Cad saúde pública [periódico na Internet].2007 [acesso em 18 jun 2010];23(2):399407. Disponível em: http://www.scielosp.org/pdf/csp/ v23n2/16.pdf

32. Pereira Neto AF. Ser médico no Brasil: o presente no passado. 2 ed. Rio de Janeiro: Fiocruz; 2009.

33. Amoretti R. A educação médica diante das necessidades sociais em saúde. Rev Bras Educ Med [periódico na Internet].2005 [acesso em 18 jun. 2010];29(2):136-46. Disponível em: http:/ /www.scielosp.org/pdf/csp/v23n2/16.pdf

34. Rios IC. Humanização: a essência da ação técnica e ética nas práticas de saúde. Rev Bras Educ Med [periódico na internet].2009 [acesso em 18 jun. 2010];33(2):253-61. Disponível em: http://www.scielo.br/pdf/rbem/v33n2/13. pdf

35. Fallat ME, Glover J, Committee on Bioethics. Profissionalism in Pediatrics. Pediatrics [periódico na Internet].2007 [aceso em 17 fev. 2010];120(4):1123-33. Disponível em: http:/ / www.pediatrics.org/cgi/content/full/120/4/ e1123

36. Rego S, Gomes AP, Siqueira-Batista R. Bioética e humanização como temas transversais na formação médica. Rev Bras Educ Med [periódico na Internet].2008. [acesso em 18 ago. 2010]; 32(4):482-91. Disponível em: http:// www.scielo.br/pdf/rbem/v32n4/v32n4a11.pdf

37. American Academy of Pediatrics. Committee on Bioethics. Profissionalism in pediatrics: statement of principles. Pediatrics. 2001;120(4):895-7.

38. Morin E. Os sete saberes necessários à educação do futuro. São Paulo / Brasília: Cortez / UNESCO; 2002.
39. Silva EL, Cunha MV. A formação profissional do século XXI: desafios e dilemas. Ci Inf 2002;31(3):77-82.

40. Batista SHS. A interdisciplinaridade no ensino médico. Rev Bras Educ Méd [periódico na Internet].2006 [acesso em 18 ago. 2010];30(1):39-46. Disponível em: http:/ / www. scielo.br/pdf/rbem/v30n1/v30n1a07.pdf

41. Cortina A. O fazer ético: guia para a educação moral. São Paulo: Moderna; 2003.

42. Garrafa V, Albuquerque MC. Enfoque bioético de la comunicación en la relación médico-paciente en las unidades de terapia intensiva pediátrica. Acta Bioethica [periódico na Internet].2001. [acesso em 18 ago 2010]; 7(2):355-67. Disponível em: http:/ / www.scielo.cl/pdf/abioeth/v7n2/ art14.pdf

\section{CONTRIBUIÇÃO DOS AUTORES}

Jucélia Maria Guedert participou da concepção e desenho do estudo,da coleta, análise e interpretação dos dados, escreveu e revisou o presente artigo eaprovou esta versão para publicação. Suely Grosseman participou da concepção e desenho do estudo, da análise e interpretação dos dados, escreveu e revisou o presente artigo eaprovou esta versão para publicação.

\section{CONFLITO DE INTERESSES}

Declarou não haver.

\section{ENDEREÇO PARA CORRESPONDÊNCIA}

Jucélia Maria Guedert

Rua Arno Lippel, 68

Trindade - Florianópolis

CEP. 88036-630 SC

E-mail: juceliaguedert@ig.com.br 